\title{
Acceptability of a Novel Telemedication Review for Older Adults in Nursing Homes in France: A Qualitative Study
}

This article was published in the following Dove Press journal: Clinical Interventions in Aging

\author{
Marie Costa $\mathbb{D}^{1,2}$ \\ Florian Correard ${ }^{3,4}$ \\ Maeva Montaleytang ${ }^{3,4}$ \\ Karine Baumstarck ${ }^{5}$ \\ Sandrine Loubière ${ }^{5}$ \\ Kahena Amichi ${ }^{6}$ \\ Patrick Villani ${ }^{7}$ \\ Stephane Honore ${ }^{3,4,8}$ \\ Aurélie Daumas ${ }^{7}$ \\ Pierre Verger ${ }^{1,2}$
}

'ORS PACA, Southeastern Health Regional Observatory, Marseille, France; ${ }^{2}$ Aix Marseille Univ, IRD, AP-HM, SSA VITROME, IHU-Méditerranée Infection, Marseille, France; ${ }^{3} \mathrm{AP}-\mathrm{HM}$, Service Pharmacie, Hôpital de la Timone, Marseille 13385, France; ${ }^{4}$ Laboratoire de Pharmacie Clinique, faculté de pharmacie, Aix-Marseille Université, Marseille I3385, France; ${ }^{5}$ EA3279, Self-Perceived Health Assessment Research Unit, Aix-Marseille University, Marseille 13385, France; ${ }^{6}$ Direction de la Recherche Clinique et de I'Innovation (DRCl), AP-HM, Marseille 13354, France; ${ }^{7}$ Service de Médecine Interne Gériatrie et Thérapeutique, $\mathrm{CHU}$ Sainte Marguerite, Assistance Publique des Hôpitaux de Marseille (AP-HM), Marseille 13274, France; ${ }^{8}$ Service de Pharmacie Clinique, Faculté de Pharmacie Timone, Aix-Marseille Université, Marseille F-13000, France

Correspondence: Marie Costa Email Mariecostal212@gmail.com
Purpose: In France, polypharmacy among older people living in nursing homes $(\mathrm{NH})$ is a major public health concern. In this context, the randomized controlled trial TEM-EHPAD was recently launched in various $\mathrm{NH}$ in southern France to evaluate the impact of implementing a novel telemedication review (TMR) on hospital admission rates of $\mathrm{NH}$ residents at high risk of iatrogenic disease. A qualitative study was integrated into the main trial study to assess general practitioners' (GP) and other NH healthcare professionals' (HP) acceptability of the proposed TMR before its implementation.

Material and Methods: A qualitative study using face-to-face semi-structured interviews was conducted with 16 HP before the beginning of the intervention. A manual thematic analysis was performed on the transcribed interviews.

Results: Four main themes emerged from the thematic analysis: HP perceptions of the TMR, difficulties related to medication management for NH residents, HP perceptions of the roles of different professionals, and facilitators of good practices. Most participants were favorable to the TMR, but some GP expressed fears about loss of control over their prescription writing.

Conclusion: This study fulfilled its objective to assess pre-intervention acceptability by GP and other HP. Results provided important information about how to adapt the TMR intervention to make it more acceptable to HP who will be involved in TEM-EHPAD. One of the main recommendations is the importance of providing participating GP with the opportunity to take part in the process of reviewing prescriptions.

Keywords: qualitative study, telemedicine, older adults, telemedication review, nursing home, acceptability study, satisfaction assessment

\section{Background}

In France, nursing homes (NH) (EHPAD in French) provide permanent accommodation for older dependent adults. Within NH, polypharmacy (5 to 9 medications) and excessive polypharmacy ( $\geq 10$ medications) which concern $54.9 \%$ and $21 \%$ of residents, respectively, ${ }^{1}$ constitute major public health issues due to their association with medicine-related illness, ${ }^{2-4}$ drug interactions, ${ }^{5,6}$ poor treatment compliance, ${ }^{7}$ and hospitalization. ${ }^{8}$ In the French NH network, general practitioners (GP) visit residents and are responsible for creating, writing and reviewing their drug prescriptions. Medications are then distributed by NH nurses.

Deprescribing is an effective way to minimize polypharmacy and improve patient outcomes. ${ }^{9}$ Previous studies exploring acceptability and expectations of 
interventions aimed at improving medication practices among HP have shown that GP are willing to receive more information about the benefits and risks of medications for elderly patients. ${ }^{10}$ However, they face patientrelated difficulties when it comes to suggesting deprescribing a medication. ${ }^{10}$ Moreover, the GP medical culture of prescribing, organizational constraints (eg, repeat prescriptions by telephone, the hectic pace of work), ${ }^{11}$ the influence of nurses and other HP opinions, ${ }^{12}$ as well as concern about withdrawal side effects, ${ }^{13}$ are all barriers to deprescribing.

In this context, the TEM-EHPAD (or Telemedicationbased prescription review (TMR) in French NH,) control trial $^{14}$ was recently launched to evaluate the impact of a novel TMR specifically designed for $\mathrm{NH}$ residents at high risk of iatrogenic disease. It is the first such trial in France.

Telemedicine is used ever increasingly worldwide, ${ }^{17}$ in particular to obtain specialist advice, especially in the fields of dermatology and cardiology. ${ }^{18-20}$ It has been proven to be an effective means of improving health and quality of life in older adults living in $\mathrm{NH}^{21}$ However, to our knowledge, no published article to date has investigated TMR or its possible benefits in the French context. ${ }^{14}$

The majority of studies on telemedicine to date have provided evidence that patients' and physicians' acceptability of this relatively new tool in primary care varies significantly according to demographic variables (eg gender, age, socioeconomic status). ${ }^{15}$ Furthermore, it has been shown that to ensure acceptability of telemedicine, special care must be taken when considering its clinical relevance, the practical aspects involved, and its impact on health professionals' roles. ${ }^{16}$ Moreover, studies highlight the importance - in terms of acceptability - of engaging future users in its development and implementation.

TEM-EHPAD's protocol provides for a total of 364 patients, randomized into two groups: (1) an experimental group (182 patients) benefiting from the TMR, and (2) a control group (182 patients) receiving standard care. The trial's main outcome is the rate of all-cause unplanned hospital admissions occurring within 3 months of randomization.

The success of the TMR, and the level and duration of its impact, will depend in part on how it is initially perceived and accepted by GP and other healthcare professionals (HP) working in NH, and how it is subsequently integrated into current healthcare practices. Indeed, it has been observed that poor acceptability of interventions by the professionals concerned jeopardizes their progress. ${ }^{22}$
The intervention protocol stipulates that the TMR's proposed prescription adjustments are to be sent to GP who can choose to either accept or reject the medication adjustments proposed. If GP are not open-minded about implementing the suggested adjustments, it will not be possible to observe the success of this intervention on different outcomes. It is therefore essential to first assess and then guarantee - by making adjustments to the original protocol - GP and other NH staff's acceptability of the proposed intervention (ie, pre-intervention), as well as their satisfaction with it (ie, post-intervention).

Accordingly, we integrated a three-phase mixed-methods study into TEM-EHPAD which aimed to assess GP and other HP acceptability of the TMR intervention (by identifying individual and contextual factors that may facilitate or complicate its implementation) before its implementation (Phase 1, qualitative study), and to assess their satisfaction with it after its implementation (Phases 2 and 3, quantitative and qualitative studies, respectively, see Figure 1). This type of mixed-method protocol is particularly suitable when developing multi-stage research programs. ${ }^{23}$ This paper presents results from Phase 1 of this acceptability/satisfaction study, which was performed between March and September 2019. Data analysis for this phase was completed in January 2020.

The objectives of the present work were to i) be able to adjust the original design of the TMR intervention, if needed, in order to ensure its acceptability to all GP and other HP working in $\mathrm{NH}$ participating in experimental testing of the novel TMR intervention, and ii) provide essential information for the design of the questionnaires to be used in Phase 2 (quantitative survey) of the study, which will involve the participation of between 150 and $200 \mathrm{HP}$. Information from Phase 1 will also permit us to observe how GP attitudes towards the experimental intervention evolve during its implementation.

\section{Method}

\section{Brief Presentation of the TEM-EHPAD Randomized Controlled Trial}

A detailed presentation of the TEM-EHPAD randomized control trial protocol was published in April 2020. ${ }^{14}$ Briefly, a total of 364 patients are randomized into two groups: (1) an experimental group (182 patients) benefiting from the telemedicine-based TMR and (2) a control group (182 patients) receiving standard care.

The TMR is undertaken by a hospital-based team composed of a clinical pharmacist and an internal medicine specialist trained in geriatrics. The team's conclusions for 


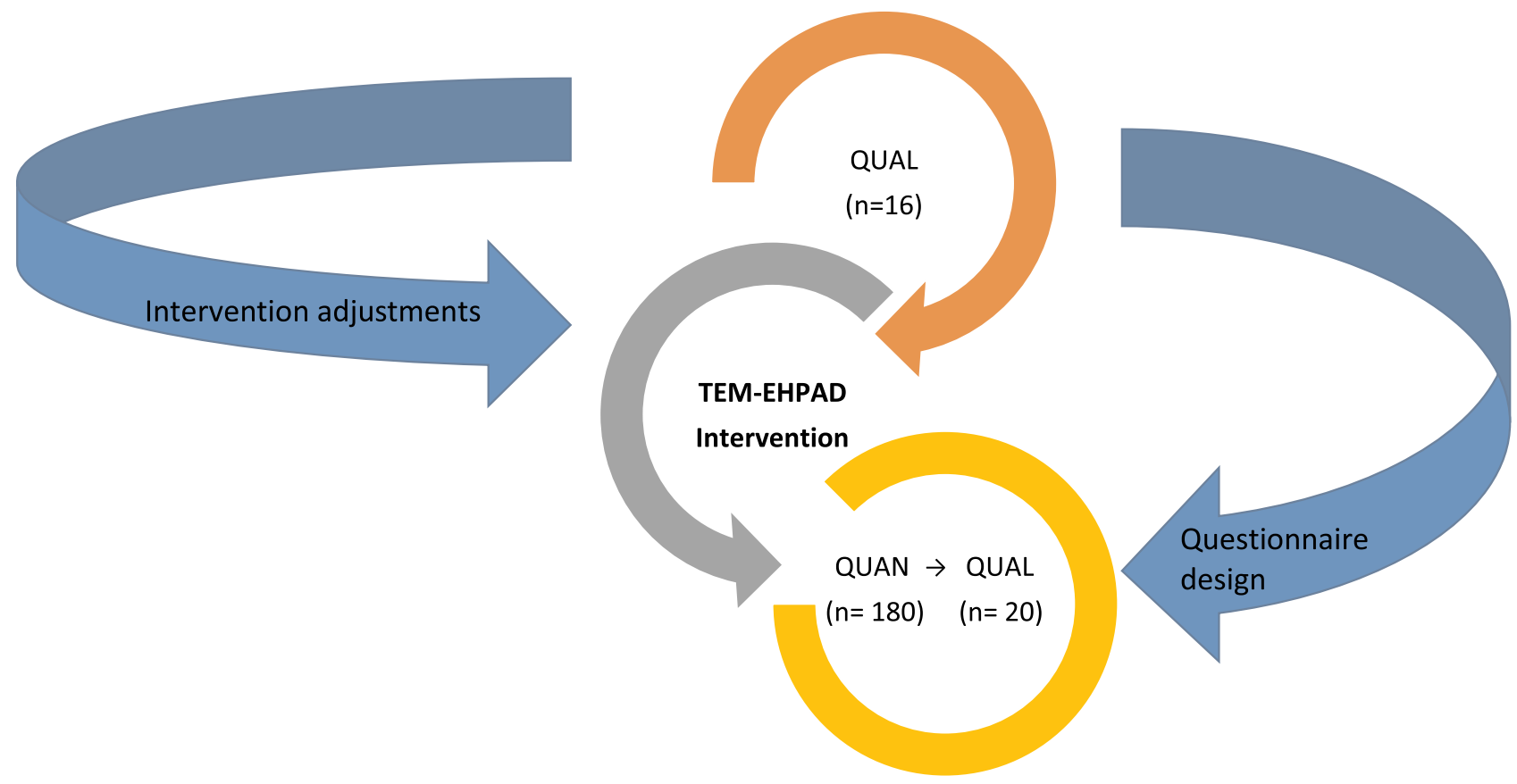

Figure I TMR acceptability of (pre-intervention) and satisfaction with (post-intervention) mixed-methods study design.

each NH resident are transmitted to HP associated with the relevant $\mathrm{NH}$, including GP. The protocol stipulates that GP may accept or reject the medication adjustments proposed by the TMR team.

Control group patients receive standard care from the medical and paramedical team of the $\mathrm{NH}$ where they reside. No medication reconciliation or medication review of their prescribed drugs is conducted.

The primary outcome is the rate of all-cause unplanned hospital admissions occurring within 3 months of randomization.

\section{General Design of the Three-Phase Mixed- Methods Acceptability/Satisfaction Study Within the TEM-EHPAD Control Trial}

The three-phase mixed-methods acceptability/satisfaction study within the TEM-EHPAD control trial aims to assess GP and NH staff's acceptability of the TMR before its implementation, and their satisfaction with it during and after its implementation (Figure 1).

\section{Phase I}

Pre-Intervention Qualitative Study Measuring HP Acceptability

Aims

This qualitative study (ie, Phase 1, completed in January
2020) aimed to assess GP and NH staff's acceptability and expectations of the proposed TMR intervention, by identifying individual and contextual factors which could facilitate or complicate the implementation of the proposed TMR.

More specifically, it aimed to:

1. Identify difficulties related to NH residents' medication management and treatment appraisal by examining discourses from a small sample of GP and NH staff who would be involved in the TMR intervention.

2. Assess GP and NH staff's expectations and fears of the TEM-EHPAD trial, and especially of the proposed TMR intervention.

3. Understand and analyze differences between various HP (ie, GP, nurses, coordinating doctors) regarding their experiences, practices and perceptions of drug management for older adults.

\section{Qualitative Study Design}

The qualitative study comprised semi-structured in-depth face-to-face interviews with HP. Data were analyzed using a manual thematic analysis. Although the creation of focus groups would also have been a worthwhile added dimension, this was not possible because of participants' scheduling constraints. 


\section{Interviewer Characteristics}

The interviews were conducted by the main investigator $\mathrm{MC}$, a female researcher with a $\mathrm{PhD}$ in Public Health, who was working as a research engineer for the French Southeastern Regional Health Observatory at the time. MC has 3 years' experience with similar studies.

No relationship was established prior to study commencement between $\mathrm{MC}$ and participants. Before each interview started, she introduced herself, the study, and its objectives.

\section{Selection of Participants}

Between March and September 2019, 16 HP working in 4 $\mathrm{NH}$ located in and around the city of Marseille in southern France were interviewed. They included GP, coordinating doctors, nurses and coordinating nurses.

It is important to underline that in France, GP who visit patients in $\mathrm{NH}$ are independent workers, not NH employees. In contrast, coordinating doctors are NH employees.

$\mathrm{MC}$ was first introduced to healthcare staff in three different $\mathrm{NH}$ on the occasion of the presentation of the proposed TEM-EHPAD trial. She presented the acceptability/satisfaction mixed-method study, and invited staff members to participate. The two coordinating doctors, three nurses and two coordinating nurses invited to participate all agreed to do so.

$\mathrm{NH}$ staff also provided MC with the contact details of GP following residents. She then contacted the latter by phone or email, explaining the study and inviting them to participate. Of the 11 GP contacted, 9 agreed to participate.

All $16 \mathrm{HP}$ agreed to participate on a voluntary basis.

\section{Data Collection}

MC performed the face-to-face interviews in a private office (NH or GP studio) to ensure confidentiality. Interviews were audio-recorded to facilitate transcription.

The interviews aimed to obtain a detailed description of i) HP experiences concerning drugs prescription/distribution for $\mathrm{NH}$ residents, and ii) their expectations and views of the proposed TMR. Interviews follow a questionnaire based on the framework detailed in Figure 2. This questionnaire was built by exploring the literature on similar topics.

\section{Ethical Approval and Consent to Participate}

The confidentiality and anonymity of participants was guaranteed for each participant in every step of the study.
No information was kept which could result in participants being identified. Audio-recorded interviews were transcribed and deleted within 3 months after recording. Only the main investigator, who also performed the transcription, had access to the recordings.

The trial protocol, including the mixed-methods study, was approved by the Sud-Est II Ethics committee in November 2018 and covers all NH sites involved in the study. The research already carried out (Phase 1) and the work to be carried out (Phases 2 and 3) are in accordance with the Helsinki declaration and ICH GCP Guidelines.

Participation in the qualitative study required written informed consent (including consent to the publication of anonymized responses) after being provided with a document explaining the modalities and objectives of the study. The same will be true for the upcoming Phases 2 (quantitative) and 3 (qualitative) of the mixed-methods study.

\section{Data Analysis}

Interviews were transcribed as intelligent verbatim using Microsoft Word, and de-identified by MC, who then performed a thematic analysis of the data. ${ }^{24}$ An inductive approach was chosen to allow themes to emerge spontaneously. First, MC read the transcripts several times and then proceeded to coding. Higher-order themes were determined by discussion between $\mathrm{MC}$ and PV. In order to ensure coding consistency, ${ }^{25,26}$ researchers met regularly to discuss their progress with the analysis. Any discrepancies were discussed until consensus was reached.

The main challenge of this analysis was to identify common themes which would group different professionals' concerns while at the same time expressing the variability of their points of view. Data saturation was reached after 13 interviews.

\section{Results}

\section{Participant Profiles}

Sixteen HP were enrolled in the qualitative study, including 3 nurses, 2 coordinating nurses, 2 coordinating doctors and 9 GP (from the 11 contacted). Ten were male and 6 were female, 6 were over 50 years old, 7 were between 30 and 50 years old and 3 were under 30 .

\section{Presentation of Themes and Sub-Themes}

Four themes and 7 sub-themes emerged from the qualitative data collected. Table 1 presents the results, themes and sub-themes and illustrates them, where possible, with 


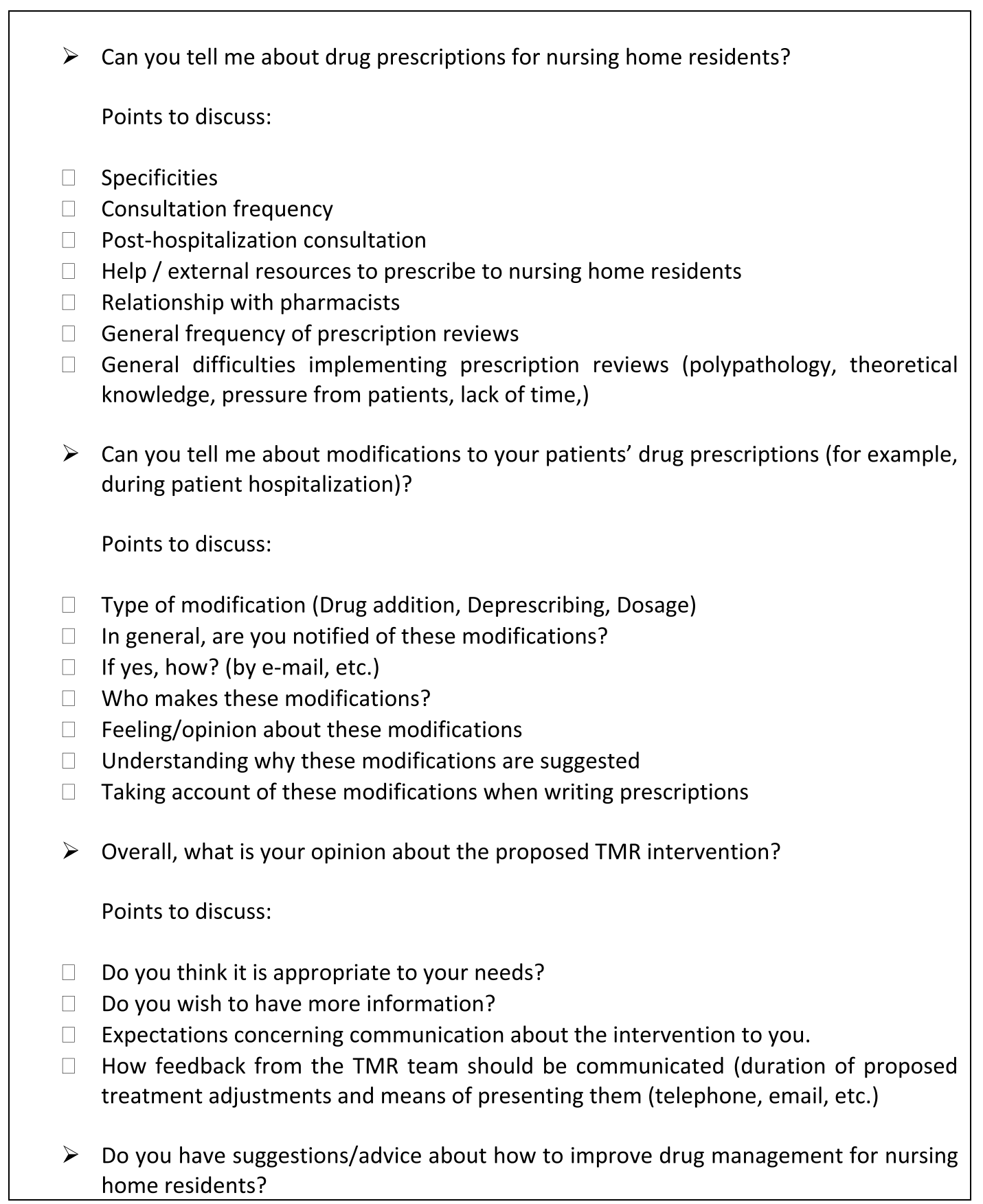

* Two interview guides were created based on existing literature: one for GP and one for other $\mathrm{NH}$ professionals (coordinating doctors, nurses, and coordinating nurses). Despite addressing the same topics, they were slightly different in content, as they were adapted to each participant's professional profile. The one presented here is the GP interview guide.

Figure 2 GP Interview Guide*. 
excerpts from HP discourses from the various professional categories (ie, GP, Coordinating Doctors, Coordinating Nurses, Nurses). Themes and sub-themes are also described in greater detail below. Extra discourse excerpts have been added for themes we deemed to be particularly pertinent.

\section{Description of Themes and Sub-Themes Difficulties Related to Medication Management for $\mathrm{NH}$ Residents}

All participants described several difficulties which occur in managing medication for NH residents. These difficulties were related to the specific profile of older adults as a group, the context of $\mathrm{NH}$, and external factors such as specialist involvement regarding prescriptions and pressure from residents' families.

\section{Specific Profile of Older Adults as a Group}

Participants agreed that it is difficult to manage medication for older adults, and provided several reasons. They expressed that these difficulties were mainly related to psychological and physiological health issues of older adults. More specifically, cognitive impairment makes conversation difficult, and consequently GP have to decide on a medical treatment without the patient's input. Furthermore, older adults were described as being very much "attached" to their drugs and reluctant to any change. Older adults are characterized by multimorbidity and therefore polypharmacy. Drugs provided to relieve one medical issue may often lead to another. Consequently, as stated by the coordinating nurse in sub-theme 1.1 (Table 1), HP must "try and keep both sides happy" when it comes to treating older adults' symptoms. GP reported that they were caught between guidelines recommending fewer drugs and the numerous patient health issues they felt needed to be addressed with drugs. One GP/investigator interaction reflects this: "There is a debate that says that after the first three or four drugs for the elderly, the rest have no effect, and even have side effects (...).

Investigator: Do you think it's possible to limit the number of drugs to 3 or 4 ?

GP: No, no, a patient with a cardiac problem needs 5 or 6 drugs for starters."

\section{Nursing Home Context}

The different HP involved in the study also agreed that there are constraints which are specific to the $\mathrm{NH}$ context.
The work shift system, which cannot be avoided in NH as they are open $24 / 247 / 7$, requires the intervention of several teams (day team, night team, weekday team, weekend team). Communication is sometimes difficult between these teams, which delays the transmission of information about changes to residents' prescriptions. Another constraint reported by several HP was the lack of drugs available in $\mathrm{NH}$ and the lack of different forms of administration (tablets, sachets, etc.) for the same medicine. In France, NH are considered accommodation facilities, not healthcare facilities, and access to various forms of administration is limited despite being necessary for individual residents. Furthermore, French law prohibits NH from having a well-supplied pharmacy in-situ: NH cannot provide PRN (ie, "as needed") drugs. Finally, NH coordinating doctors reported that geriatrics is still a recent specialty, and there are not yet enough suitable drugs available for older adults.

\section{External Factors}

External factors include medication-related difficulties not specific to either NH or older adults which can take various forms. Participants had different views on these factors depending on their profession. For GP, external factors mainly comprised pressure from families and involvement by other HP outside the NH. More specifically, they reported that families do not accept that their parents are getting older and will not get better. They mentioned that families ask them to sedate their parents, are often reluctant to any change in medication, and also ask other HP for advice, in the hope of finding a cure for their parents. One GP said: "We follow them, but we cannot cure them, we cannot rejuvenate them. Families seem to expect us to cure, to rejuvenate them, but we cannot."

With regard to the involvement of other HP, especially specialists, GP considered that they prescribe too many drugs.

NH staff's views reflected those of GP regarding family-related difficulties. However, they also pointed out that GP sometimes forget to review their own prescriptions, prescribe too many drugs, and do not agree to deprescribing even when asked to do so by nurses and coordinating doctors. One NH staff member said:

I think that there are GP who prescribe too many drugs. It is true that sometimes they are a little lost in the routine of it all, and so they repeat the treatments. Sometimes they are in a hurry, so they renew the prescription automatically. 
Table I Presentation of Themes and Sub-Themes and Related Interview Discourse Excerpts According to Professional Category

\begin{tabular}{|c|c|c|c|c|}
\hline & GP & Nurse & Coordinating Nurse & Coordinating Doctor \\
\hline \multicolumn{5}{|c|}{ I. Difficulties related to drug management for NH residents } \\
\hline & $\begin{array}{l}\text { Impossibility to discuss drug } \\
\text { management with the } \\
\text { patient because of impaired } \\
\text { cognitive function }\end{array}$ & $\begin{array}{l}\text { Patient attachment to } \\
\text { medications }\end{array}$ & Vigilance over side effects & Difficulty changing habits \\
\hline \multirow[t]{2}{*}{$\begin{array}{l}\text { I.I Specific } \\
\text { profile of } \\
\text { older adults } \\
\text { as a group }\end{array}$} & $\begin{array}{l}\text { "Most of the time, we have to } \\
\text { deal with people who have } \\
\text { severe cognitive impairment, } \\
\text { and I can't write out a drug } \\
\text { prescription in a shared [ie with } \\
\text { the patient] well-reasoned } \\
\text { manner." }\end{array}$ & $\begin{array}{l}\text { "For example, Mrs B takes } 10 \\
\text { tablets in the morning, and } 10 \\
\text { tablets in the evening: It's tragic, } \\
\text { but we can't take them from } \\
\text { her. She counts them. If there's } \\
\text { one missing, she notices. She } \\
\text { has a psychological issue and } \\
\text { she's very attached to her drugs. } \\
\text { It's terrible." }\end{array}$ & $\begin{array}{l}\text { "You give morphine, so you're } \\
\text { going to have to monitor the } \\
\text { side effects of morphine. } \\
\text { Constipation becomes a } \\
\text { disaster, and you have to do a } \\
\text { faecal extraction every day, so } \\
\text { you have to try and keep both } \\
\text { sides happy." }\end{array}$ & $\begin{array}{l}\text { "They've been taking this } \\
\text { medication all their life, so any } \\
\text { change upsets them." }\end{array}$ \\
\hline & Communication problems & $\begin{array}{l}\text { Choice of administration } \\
\text { form }\end{array}$ & Unavailability of some drugs & Unavailability of some drugs \\
\hline \multirow[t]{2}{*}{$\begin{array}{l}\text { I.2 Nursing } \\
\text { home } \\
\text { context }\end{array}$} & $\begin{array}{l}\text { "That's a little bit more } \\
\text { complicated in the nursing } \\
\text { home context. Indeed, there's } \\
\text { often a small delay in } \\
\text { information transmission. There } \\
\text { are regular communication } \\
\text { problems, different teams do } \\
\text { different shifts and they don't } \\
\text { know each other." }\end{array}$ & $\begin{array}{l}\text { "She cannot swallow, so I had to } \\
\text { give her a suppository. It's not } \\
\text { the best treatment choice." }\end{array}$ & $\begin{array}{l}\text { "We may also require 'as } \\
\text { needed' medicines. For } \\
\text { example, patients will ask us for } \\
\text { pain killers, but we don't have } \\
\text { any in our medicine trolley." }\end{array}$ & $\begin{array}{l}\text { "We don't have access (in NH) to } \\
\text { the same medications that } \\
\text { hospitals have. We don't have the } \\
\text { same forms of administration. for } \\
\text { drugs. There are some drugs that } \\
\text { cannot be found in the pharmacy. } \\
\text { Sometimes we receive } \\
\text { prescriptions from the hospital } \\
\text { but we get stuck because they } \\
\text { prescribe a medicine that isn't at } \\
\text { the pharmacy." }\end{array}$ \\
\hline & $\begin{array}{l}\text { Difficulties collaborating } \\
\text { with other HP }\end{array}$ & & Disinterest of locum GP & $\begin{array}{l}\text { NH residents “family- } \\
\text { related" difficulties }\end{array}$ \\
\hline $\begin{array}{l}\text { I.3 External } \\
\text { factors }\end{array}$ & $\begin{array}{l}\text { "In general, neurologists } \\
\text { prescribe a lot, and when we } \\
\text { take away their medications, we } \\
\text { must be careful to do things } \\
\text { gradually (...). They've been } \\
\text { prescribed by other doctors; } \\
\text { we've got to be careful about } \\
\text { their being sensitive. Especially } \\
\text { specialists, in particular } \\
\text { psychiatrists ..." }\end{array}$ & & $\begin{array}{l}\text { "(...) Some of them [ie, locum } \\
\text { GP] refuse to consult; the } \\
\text { doctor who came yesterday } \\
\text { refused to consult a patient who } \\
\text { was right in front of him } \\
\text { because he had no time and } \\
\text { because it was his last day to } \\
\text { substitute." }\end{array}$ & $\begin{array}{l}\text { “(...) families and residents, it's } \\
\text { hard, (...), we must explain, but } \\
\text { residents, even though they have } \\
\text { their cognitive abilities, there are } \\
\text { some who we can talk to; with } \\
\text { others, it's difficult. Sometimes } \\
\text { you have to explain it to them. } \\
\text { Then, you have to discuss it with } \\
\text { their family. Well, there are two or } \\
\text { three families - not the majority - } \\
\text { but they're difficult ...” }\end{array}$ \\
\hline \multicolumn{5}{|c|}{ 2. Perceptions of different professional roles } \\
\hline & $\begin{array}{l}\text { Importance of being open- } \\
\text { minded about adopting } \\
\text { TMR team's proposed } \\
\text { changes to prescriptions }\end{array}$ & Nurses' role & Nurses' role & $\begin{array}{l}\text { Advisory role of } \mathrm{NH} \\
\text { coordinating doctors }\end{array}$ \\
\hline
\end{tabular}

(Continued) 
Table I (Continued).

\begin{tabular}{|c|c|c|c|c|}
\hline & GP & Nurse & Coordinating Nurse & Coordinating Doctor \\
\hline \multirow[t]{2}{*}{$\begin{array}{l}\text { 2.I HP } \\
\text { perceptions } \\
\text { of their own } \\
\text { role }\end{array}$} & $\begin{array}{l}\text { "Implementing prescription } \\
\text { changes is a responsibility. For } \\
\text { instance, tomorrow, if I do not } \\
\text { apply a new medication set out } \\
\text { by the hospital, if something } \\
\text { happens, and then if the family } \\
\text { says to me: "my mother died } \\
\text { three days ago, because she left } \\
\text { the hospital and you did not } \\
\text { follow the new medication set } \\
\text { out by the hospital ". In my } \\
\text { opinion, it would be my fault } \\
\text { and I could be sued." }\end{array}$ & $\begin{array}{l}\text { "Well, I take care of the } \\
\text { medicine trolleys, receiving } \\
\text { medications [ie, from the } \\
\text { pharmacy], I check if they've } \\
\text { given the right medication, I } \\
\text { adjust them according to } \\
\text { treatment changes. Today for } \\
\text { example, there have been a lot } \\
\text { of treatment changes." }\end{array}$ & $\begin{array}{l}\text { "I don't administer a } \\
\text { prescription haphazardly. I think } \\
\text { about it, I do as I was taught; I } \\
\text { call it 'the doubt culture"”. }\end{array}$ & $\begin{array}{l}\text { "It is also the role of } \\
\text { coordinating doctors to } \\
\text { intervene with general } \\
\text { practitioners, to help them to } \\
\text { choose the most appropriate } \\
\text { drugs." }\end{array}$ \\
\hline & $\begin{array}{l}\text { Importance of nursing } \\
\text { assistants }\end{array}$ & & $\begin{array}{l}\text { Need for GP who care } \\
\text { about NH residents }\end{array}$ & GP as decision makers \\
\hline $\begin{array}{l}2.2 \mathrm{HP} \\
\text { perceptions } \\
\text { of the roles } \\
\text { of other HP }\end{array}$ & $\begin{array}{l}\text { "When I ask the nurse about } \\
\text { the patient's [intestinal] transit, } \\
\text { he or she asks the nursing } \\
\text { assistant. It's the assistant who's } \\
\text { closest to the patient, and when } \\
\text { l'm told that a patient is in pain, } \\
\text { it's the assistant who reported } \\
\text { it. Pain assessment, they're [ie, } \\
\text { nursing assistants] the ones that } \\
\text { do it." }\end{array}$ & & $\begin{array}{l}\text { "(What do we need?) General } \\
\text { practitioners who are available, } \\
\text { who come here often to see } \\
\text { their patients. It's true that } \\
\text { when they follow few residents, } \\
\text { or just one, they don't even } \\
\text { come to renew prescriptions." }\end{array}$ & $\begin{array}{l}\text { "We [ie, coordinating doctors] } \\
\text { can give advice, but there must } \\
\text { be someone who decides, the } \\
\text { general practitioner is the } \\
\text { person who the resident trusts, } \\
\text { he's the one who decides." }\end{array}$ \\
\hline \multicolumn{5}{|c|}{ 3. Facilitators of good practice } \\
\hline & $\begin{array}{l}\text { Collaboration and mutual } \\
\text { help between GP in NH }\end{array}$ & $\begin{array}{l}\text { Rolled-up medicine sachet } \\
\text { drug distribution system }\end{array}$ & Availability of GP & $\begin{array}{l}\text { Importance of having a } \\
\text { small number of GP } \\
\text { working in the same NH }\end{array}$ \\
\hline & $\begin{array}{l}\text { "I follow I0 patients, I come } \\
\text { once a week, but there are my } \\
\text { colleagues, who are here on } \\
\text { other days; when I'm here, I } \\
\text { consult their patients as well as } \\
\text { mine, and when they are here, } \\
\text { and I'm not, they consult mine." }\end{array}$ & $\begin{array}{l}\text { "Now, we have a 'snail' [ie, } \\
\text { rolled-up medicine sachet] drug } \\
\text { distribution system. Well, I think } \\
\text { it works very well. Before that, } \\
\text { we spent a lot of time preparing } \\
\text { the drugs. Well, now, we just } \\
\text { have to be careful and check } \\
\text { which drugs we distribute; I } \\
\text { think it works well." }\end{array}$ & $\begin{array}{l}\text { "(...) we have general } \\
\text { practitioners who answer the } \\
\text { phone when we have a problem; } \\
\text { we talk about it, we have the } \\
\text { answer, not immediately, but I } \\
\text { would say in the next half hour." }\end{array}$ & $\begin{array}{l}\text { "It's easy because there was } \\
\text { doctor J. who followed all the } \\
\text { residents; he ended up sharing } \\
\text { patients with another doctor; } \\
\text { he went into partnership with } \\
\text { him; (...) only one resident kept } \\
\text { his own general practitioner, it's } \\
\text { easier to manage } 2 \text { general } \\
\text { practitioners than } 20 . "\end{array}$ \\
\hline \multicolumn{5}{|c|}{ 4. Views about the TMR intervention } \\
\hline & $\begin{array}{l}\text { TEM-EHPAD viewed as an } \\
\text { opportunity to "take } \\
\text { control" of NH residents' } \\
\text { prescriptions }\end{array}$ & $\begin{array}{l}\text { TEM-EHPAD viewed as an } \\
\text { opportunity to improve } \\
\text { practices }\end{array}$ & $\begin{array}{l}\text { TEM-EHPAD viewed as an } \\
\text { opportunity to improve } \\
\text { practices }\end{array}$ & $\begin{array}{l}\text { TEM-EHPAD viewed as an } \\
\text { opportunity to improve } \\
\text { practices }\end{array}$ \\
\hline
\end{tabular}

(Continued) 
Table I (Continued).

\begin{tabular}{|c|c|c|c|c|}
\hline & GP & Nurse & Coordinating Nurse & Coordinating Doctor \\
\hline \multirow[t]{2}{*}{$\begin{array}{l}4.1 \\
\text { Expectations } \\
\text { and positive } \\
\text { views }\end{array}$} & $\begin{array}{l}\text { "In my opinion, I don't think it'll } \\
\text { bring me much, because I think I } \\
\text { have enough experience making } \\
\text { the right prescriptions ... But for } \\
\text { sure, there'll definitely be a few } \\
\text { small things. I'm not fully in } \\
\text { charge of my prescriptions yet } \\
\text { [because he was newly arrived } \\
\text { in the NH at the time]. There'll } \\
\text { definitely be small changes; It'll } \\
\text { be the chance to get a message } \\
\text { across, so why not." }\end{array}$ & $\begin{array}{l}\text { "I don't know, we can always } \\
\text { evolve, we discussed the project } \\
\text { a little bit, but I don't really } \\
\text { know what it'll bring us." }\end{array}$ & $\begin{array}{l}\text { "There is always a point to } \\
\text { having external advice about } \\
\text { treatments." }\end{array}$ & $\begin{array}{l}\text { "Perhaps a review of } \\
\text { prescriptions ... It is true that } \\
\text { sometimes, when there's no } \\
\text { issue, we renew but we don't } \\
\text { reassess utility of each } \\
\text { treatment. We do that only } \\
\text { when a new resident arrives, } \\
\text { because they've just arrived, we } \\
\text { don't know them, we look at } \\
\text { the medical history. After, } \\
\text { sometimes, with the routine of } \\
\text { it all, we forget. A fresh look } \\
\text { could be useful.” }\end{array}$ \\
\hline & Reduced freedom & & $\begin{array}{l}\text { Doubts about the TMR } \\
\text { intervention }\end{array}$ & \\
\hline $\begin{array}{l}4.2 \text { Fears and } \\
\text { negative } \\
\text { views }\end{array}$ & $\begin{array}{l}\text { "Maybe this is the future of } \\
\text { medicine - an evaluation } \\
\text { committee! Before, we dealt } \\
\text { with patients, we could } \\
\text { prescribe according to our } \\
\text { experience, our know-how, etc. } \\
\text { Apparently, that's all over. We'll } \\
\text { be stuck between patient } \\
\text { demands on the one hand, and } \\
\text { an evaluation committee on the } \\
\text { other." }\end{array}$ & & $\begin{array}{l}\text { "If she has had a treatment for } \\
10 \text { years, and everything is going } \\
\text { well, even if she takes } 15 \text { tablets } \\
\text {... ? Well, I wouldn't change the } \\
\text { treatment." }\end{array}$ & \\
\hline
\end{tabular}

\section{HP Perceptions of the Roles of Different Professionals}

Participants were very specific when describing what they perceived as their own role and duties, and what they expected other HP to do.

\section{HP Perceptions of Their Own Role}

With regard to the follow-up of $\mathrm{NH}$ residents, GP explained that they felt they have to be available, vigilant and adaptable, and that one of their main roles was to manage medications, taking into account opinions and advice from residents and other HP. Coordinating doctors shared similar views about their own role. The majority of GP recognized the legitimacy of the proposed hospitalbased TMR team to review residents' prescriptions.

Nurses reported that they have to be rigorous in their work practices and emphasized that not only do they have to administer drugs, they must also evaluate the appropriateness of prescriptions before administrating them.

\section{HP Perceptions of the Roles of Other HP}

GP expected coordinating doctors to advise them when prescribing drugs, and expected nurses to provide information concerning NH residents' health. They valued the role of nurses, which they perceived to be very difficult, and their help in providing information. One GP said:

It's not easy; it's not easy for the nurses; it's not easy for the nursing assistants. The nursing assistants are paid peanuts and they work hard. I wouldn't do their job for anything in the world. I have a lot of respect for them; they're on the front line.

Nurses expected GP to be available and concerned about residents' health and well-being.

\section{Facilitators of Good Practice}

Participants mentioned some facilitators in drug management of NH residents. All agreed that having a small number of GP in an NH was a major facilitator: when GP follow several residents, they visit them often, and have a good knowledge 
of their patients and of NH organization and staff. GP also reported that their working experience with older adults and their background were important facilitators for good practice, as was a good collaboration with both NH staff and hospital staff when NH patients are hospitalized. They also explained that when a patient is newly admitted to an $\mathrm{NH}$, they "spring clean" her/his prescriptions, deprescribing all useless and inappropriate drugs. This also helped them in patient follow-up. One GP said:

Well, in general, when they arrive, they have a plethora of drugs that we try to reduce. It's not unusual to see patients arriving with 10 or 12 drugs, which, in my opinion, is useless.

Prescription software packages were described as helpful, but some GP mentioned that they do not work very well, and require a lot of upstream work (eg, the need to type in a full medical history for each patient). Only one GP mentioned resorting to a "geriatric medical check-up", which consists of sending a new resident to the hospital for 1 day in order to obtain a full medical check-up and recommendations regarding the patient's treatment.

Recently, a new drug distribution system has been implemented in many NH in France. Drugs are prepared by robots and come in the form of rolled-up medicine sachets for each resident. They are commonly called "snails" in France, because of their appearance. As stated in Table 1, some nurses found this system helpful. However, several also reported that it makes treatment changes more difficult.

Coordinating doctors and nurses, respectively, identified prescription guidelines and GP involvement as primary facilitators of good practice.

\section{HP Perceptions of the TMR Intervention \\ Expectations and Positive Perceptions}

Overall, most participants perceived the TMR intervention as an opportunity to improve their professional practices and were favorable to receiving advice and support.

GP who strove to keep control over their prescription writing perceived the intervention as an opportunity to strengthen that control, especially for patients also followed by other doctors (ie, cardiologists, etc.). These GP expected that the recommendations at the end of the experimental period would reflect their current practices. Accordingly, they saw it as a way to regain legitimacy and strengthen their professional worth.

Given that NH residents and their families are sometimes reluctant to have prescriptions changed, GP expected that the TMR intervention would facilitate discussion of this subject with these stakeholders about reducing, stopping or changing inappropriate drugs.

"I am going to take these recommendations into account. I will see how it goes with patients, I will print them out and I will see." (GP)

As mentioned in Table 1 (sub-theme 4.1), coordinating doctors mainly saw the intervention as a way to make GP aware of the need to reduce the number of drugs they prescribed, a message they felt was generally difficult to get across.

\section{Fears and Negative Views}

The TMR intervention also raised some fears among the various HP. GP expressed most concerns. First, they were afraid that it would lead to their practices being controlled. Three GP also reported being afraid of and disappointed with the proposed intervention, because they associated it with a loss of professional worth. Professional worth can be described as the "process where an individual acquires the knowledge, skills, behaviors, attitudes and values of a particular profession and develops a professional identity". ${ }^{27-29}$ They perceived the project as symptomatic of a new age of medicine, where physicians are progressively losing control. Moreover, they felt that the intervention inherently threw doubt on their capacity as physicians and nullified their experience.

It is presented as an improvement in therapeutic care. It makes me feel guilty, because if it is an improvement, that means that until now, it [ie, therapeutic care] wasn't that good. (GP)

These GP were also reluctant about telemedicine in general. They considered that fieldwork is very different from theory, and that it is difficult to apply guidelines and recommendations in the field.

Other GP had quite a favorable attitude towards the intervention but feared it would add to their workload. Most GP explained that they wanted it to be "simple" and that the adjustments proposed be "as short as possible". One GP indicated that he did not consult his emails and preferred telephone contact.

One NH employee expressed the opinion that reducing the number of medicines for a patient is not always the best choice: if a medicine is working, deprescribing it may be associated with the pathology returning. Furthermore, one coordinating doctor indicated that the recruitment of patients to participate in the trial (which had already started at the 
time of the qualitative study and which was the responsibility of the coordinating doctors of each $\mathrm{NH}$, not the researchers) was turning out to be much more tedious than she had expected, due to the reluctance of patients, family intervention and the complexity of information notices. Indeed, she called for these notices to be made shorter and simplified.

\section{Discussion}

The mixed-methods (ie, qualitative and quantitative) study integrated into the TEM-EHPAD randomized controlled trial is particularly innovative as it studies both HP acceptability of (Phase 1, pre-intervention, completed in January 2020) and satisfaction with (Phases 2 and 3, post-intervention, planned for late 2020) a novel TMR intervention for $\mathrm{NH}$ patients. To date, similar projects examining both study feasibility and post-study evaluation have only used either a qualitative or quantitative survey, ${ }^{30-32}$ or have focused solely on post-intervention evaluation. ${ }^{33,34}$

The analysis of the results from our qualitative study was completed in January 2020. Results suggest that the intervention may help to solve several difficulties encountered by HP who treat $\mathrm{NH}$ residents. The practical implications of the acceptability of the TMR are presented in detail in Table 2. Specifically, it lists the major difficulties reported by HP concerning NH residents' medication as well as HP fears and expectations related to the TMR intervention, and how it could be adjusted to address these issues. For example, HP reported that older adults are sometimes reluctant to changes in prescriptions (ie, reduction or deprescribing of medications). This reflects results from other studies exploring similar issues. ${ }^{35,36}$ As also suggested by our study participants, we imagine that the prescription adjustments proposed by the hospital-based TMR team will convince patients of the importance of changing their prescriptions. However, previous studies showed that older adults tend to trust their GP and are reluctant to question them about their prescriptions. ${ }^{37}$ Results from both the TEM-EHPAD randomized controlled trial and the present HP acceptability/satisfaction study will provide us with a better understanding of both $\mathrm{NH}$ residents' trust in the TMR intervention's hospital-based team, and the role that this trust can play in persuading patients to agree to prescription changes.

In accordance with other findings, our results from the qualitative study showed that $\mathrm{NH}$ residents' families are often very concerned about the healthcare provided to their parents. ${ }^{38}$ This involvement can have both positive and negative $^{39}$ impacts on medication management. In our study, HP reported that family members sometimes refuse changes to their parents' medication. The TMR intervention could therefore be an opportunity to discuss with families about their parents' health, and explain to them the benefit of changing or reducing medications.

The intervention will provide support and advice to those GP who mentioned feeling alone when having to write a prescription without input from the patient because of the latter's cognitive impairment. The members of the hospitalbased TMR team are very well acquainted with all suitable medical treatments for older adults, recently approved drugs, and different existing forms of administration. This fact may help HP working in NH to choose the most appropriate treatment.

The qualitative study also allowed us to identify facilitators that help HP working in NH in the medication management of NH residents. Most HP reported that having very few GP intervening in an NH improves medication management practices. Indeed, a previous study suggested that having a large number of GP working in the same NH was associated with an increase of potentially inappropriate drug prescriptions. ${ }^{40}$ The TMR intervention cannot solve this issue, but all GP with patients randomized to the intervention arm of the TEM-EHPAD controlled trial will receive the TMR team's suggested prescription adjustments for each patient, and this could lead to a certain level of standardization of practices.

In addition, during the qualitative study, participants spontaneously described how they perceived their own roles and duties, and what they expected from other HP. In particular, GP expressed that one of their main roles was to manage medications. Previous work exploring the consequences for GP of a program promoting externally based prescription reviews showed how external steering nullified GP prescribing autonomy. ${ }^{41}$ Furthermore, skepticism ${ }^{42}$ and misconceptions about telemedicine ${ }^{43}$ have been identified as barriers to its implementation. Previous studies have suggested that implementation strategies to promote the use of telehealth should include education and support for this new way of working. ${ }^{44}$

Our results highlight that one of the major challenges for the TMR intervention is to provide GP with advice about $\mathrm{NH}$ residents' medications, without making them feel that their prescription-writing autonomy is being threatened. One possible solution could be to give GP the opportunity to actively take part in the process of prescription reviews with the intervention's hospital-based team using a participatory design. This type of design involves future users in an innovation process, ${ }^{45}$ in this case, a telemedicine-based service. The importance of conducting usability evaluations when 
Table 2 Compatibility Between Phase I Results and the TMR Intervention

\begin{tabular}{|c|c|c|c|}
\hline \multicolumn{2}{|c|}{$\begin{array}{l}\text { Issue or Concern Raised by Results from } \\
\text { Phase I of the Mixed-Methods Study }\end{array}$} & Opportunity Offered by the Intervention & Proposed Prescription Adjustments \\
\hline \multicolumn{4}{|c|}{ Difficulties related to $\mathrm{NH}$ residents' medication management } \\
\hline \multirow[t]{3}{*}{$\begin{array}{l}\text { Profile } \\
\text { of older } \\
\text { adults }\end{array}$} & $\begin{array}{l}\text { Difficulty speaking with people } \\
\text { who have severe cognitive } \\
\text { impairment }\end{array}$ & $\begin{array}{l}\text { GP will be provided support when writing prescriptions } \\
\text { for } \mathrm{NH} \text { residents and will not be alone in the decision- } \\
\text { making process }\end{array}$ & \\
\hline & $\begin{array}{l}\text { "Attachment" of older adults to } \\
\text { their medications }\end{array}$ & $\begin{array}{l}\text { Prescription adjustments proposed by the TMR hospital- } \\
\text { based team might convince patients of the need to } \\
\text { reduce or change their medications }\end{array}$ & \\
\hline & $\begin{array}{l}\text { Difficulty providing medication to } \\
\text { patients with several } \\
\text { comorbidities }\end{array}$ & $\begin{array}{l}\text { The TMR team will bring a fresh point of view and will } \\
\text { make a comprehensive review of patient's medical } \\
\text { profile, consequently leading to more appropriate } \\
\text { prescriptions }\end{array}$ & \\
\hline \multirow[t]{3}{*}{$\begin{array}{l}\text { Nursing } \\
\text { home } \\
\text { context }\end{array}$} & $\begin{array}{l}\text { Difficulty related to different } \\
\text { work shifts }\end{array}$ & & $\begin{array}{l}\text { Informing all NH employees and GP about the control } \\
\text { trial and communicating the prescription adjustments } \\
\text { proposed by the TMR team }\end{array}$ \\
\hline & $\begin{array}{l}\text { Lack of different forms of } \\
\text { medication administration in } \mathrm{NH}\end{array}$ & $\begin{array}{l}\text { It is possible that some GP are not aware of all available } \\
\text { forms of administration especially when they are new. } \\
\text { The TMR team may have a greater knowledge of these } \\
\text { items and perhaps a greater knowledge of the different } \\
\text { drugs suitable for older adults }\end{array}$ & \\
\hline & $\begin{array}{l}\text { Restricted drug availability in } \mathrm{NH} \\
\text { in-situ pharmacies }\end{array}$ & & \\
\hline \multirow[t]{3}{*}{$\begin{array}{l}\text { External } \\
\text { factors }\end{array}$} & Pressure from families & $\begin{array}{l}\text { The hospital-based TMR team may be perceived as } \\
\text { having more legitimacy to prescribe and modify } \mathrm{NH} \\
\text { residents' medications }\end{array}$ & $\begin{array}{l}\text { Informing families about the trial study, its design and } \\
\text { purposes }\end{array}$ \\
\hline & $\begin{array}{l}\text { Intervention of too many GP in } \\
\text { the same } \mathrm{NH}\end{array}$ & $\begin{array}{l}\text { The same standardized prescription procedure will be } \\
\text { applied to all residents in all } \mathrm{NH}\end{array}$ & $\begin{array}{l}\text { Informing GP about the project and communicating } \\
\text { proposed prescription adjustments }\end{array}$ \\
\hline & $\begin{array}{l}\text { Prescriptions from different } \\
\text { specialists }\end{array}$ & $\begin{array}{l}\text { The same standardized prescription procedure will be } \\
\text { applied to all residents in all } \mathrm{NH}\end{array}$ & $\begin{array}{l}\text { Informing all HP about the project and communicating } \\
\text { the TEM-EHPAD controlled trial recommendations }\end{array}$ \\
\hline \multicolumn{4}{|c|}{ Views about the TEM-EHPAD controlled trial } \\
\hline \multirow[t]{4}{*}{$\begin{array}{l}\text { Fears } \\
\text { and } \\
\text { negative } \\
\text { views }\end{array}$} & Fear of being controlled & & $\begin{array}{l}\text { Organizing a meeting with all GP who might participate } \\
\text { in the trial to reassure them about its purpose } \\
\text { Contact all GP by telephone to ask them if they have } \\
\text { questions or comments about the trial }\end{array}$ \\
\hline & Fear of additional workload & & $\begin{array}{l}\text { Ensuring the TMR team proposes only a small number of } \\
\text { adjustments to a prescription } \\
\text { Not asking HP for any feedback or for recommendations } \\
\text { about possible improvements to the intervention }\end{array}$ \\
\hline & $\begin{array}{l}\text { Worsening of NH resident's } \\
\text { health status due to the } \\
\text { interruption or modification of } \\
\text { their medications }\end{array}$ & & $\begin{array}{l}\text { Providing all HP who might be impacted by the study } \\
\text { with a contact number for the TMR team, so they can } \\
\text { promptly discuss any concerns or any potential } \\
\text { undesirable effects caused by the intervention }\end{array}$ \\
\hline & $\begin{array}{l}\text { Patient reluctance to be enrolled } \\
\text { in the study }\end{array}$ & & $\begin{array}{l}\text { Writing simpler intervention information notices for } \mathrm{NH} \\
\text { residents and their families, and providing training for the } \\
\text { coordinating doctors who enroll participants in the trial } \\
\text { such that they present the intervention in a clear and } \\
\text { positive manner. }\end{array}$ \\
\hline
\end{tabular}


developing new medication reconciliation tools has been underlined. $^{46}$ Involving HP and especially GP in the development of the TMR intervention - for example, by asking them how they would prefer to be informed about the TMR team's conclusions for a given patient and how to proceed accordingly - may increase the intervention's chances of success, and of the level and duration of its impact.

Furthermore, our results suggest that communication issues within $\mathrm{NH}$ are very common. For example, GP encounter difficulties when they wish to discuss treatment modifications with NH residents, their families, specialists, and other GP. This highlights the importance of clear, open communication between HP and between HP and patients. Indeed, previous studies focusing on communication in the clinical context found that a lack of communication between HP can result in care degradation. ${ }^{47-49}$ Accordingly, providing GP with discussion aids and training to strengthen their communication skills in this area, is important to ensure the effectiveness of this novel TMR intervention.

One of the objectives of the qualitative study (ie, Phase 1 of the three-phase mixed methods study) was to build a questionnaire which is currently being developed and which will be used in Phase 2 (which focuses on HP post-intervention satisfaction). Based on the results presented here, we plan to include questions related to difficulties raised by participants in the qualitative study (eg, "Did the intervention help you to communicate with your patients/their families?"; "Did the intervention help you to choose more appropriate drugs for your NH patients?"). Furthermore, several questions will explore how participants have perceived and experienced the project, especially concerning the perceived loss of professional autonomy among GP.

One of the main limitations of the work presented here is related to potential selection bias. GP who agreed to participate in Phase 1 may be particularly interested in NH-related topics and may not represent the diversity of profiles of French GP working in NH. However, GP who participated in Phase 1 expressed diverse views and provided very different opinions concerning both the TMR intervention and medication management of $\mathrm{NH}$ residents. Another limitation is the small sample size $(\mathrm{N}=16)$, which was dictated by small total number of potential participants, and by HP schedule constraints. However, data saturation - an important criterion in qualitative methods to determine the number of participants which is necessary - was reached after 13 interviews as no new theme emerged. This is in line with previous publications showing that 16 interviews or fewer may be sufficient for studies conducted among homogeneous groups. ${ }^{50}$

\section{Conclusion}

Phase 1 of the mixed-methods study which was integrated into the TEM-EHPAD randomized controlled trial, investigated HP acceptability of the proposed TMR intervention and fulfilled its objectives.

This intervention could provide HP with valuable help to improve their practices concerning medication management of $\mathrm{NH}$ residents. In order for the trial to be successfully implemented, information about it must be abundant, clear and fully communicated to all the stakeholders. Additional information must be given to reticent GP to assure them that they remain the primary decision-makers and have complete autonomy over their prescription writing. Furthermore, HP involved in the intervention should be given the means to contact the TEM-EHPAD team quickly, in case they have questions or concerns about the team's proposed prescription adjustments. Overall, the main challenge for the researchers and staff overseeing the implementation of the TEM-EHPAD trial will be to ensure that HP are actively involved in the TMR process and remain open-minded about the proposed prescription adjustments made by the TMR team.

\section{Abbreviations}

GP, general practitioner; HP, healthcare professional; NH, nursing home; TMR, telemedication review.

\section{Data Sharing Statement}

In order to respect participants' anonymity and confidentiality, data cannot be shared.

\section{Ethical Approval and Consent to Participate}

The trial protocol, including the mixed-methods study, was approved by the Sud-Est II Ethics committee in November 2018 and covers all NH sites involved in the study. The research already carried out (Phase 1) and the work to be carried out (Phases 2 and 3) are in accordance with the Helsinki declaration and ICH GCP Guidelines.

The confidentiality and anonymity of participant data will be guaranteed for all participants in every step of the study; no information will be kept which could result in participants being identified. Audio-recorded interviews will be transcribed and deleted within 3 months after recording. Only the main investigator (MC) will have access to the 
recordings. Participation in the qualitative study required written informed consent (including consent to the publication of anonymized responses) after being provided with a document explaining the modalities and objectives of the study. The same will be true for the upcoming Phases 2 (quantitative) and 3 (qualitative) of the mixed-methods study.

\section{Acknowledgments}

The sponsor is represented by Assistance Publique, Hôpitaux de Marseille, France. The authors thank the NH patients recruited to date in the TEM-EHPAD controlled trial, and all the healthcare professionals involved in Phase 1 of the mixed-methods study. We also thank the directors of the following nursing home groups: Korian (Ms. Hakopian, Ms. Amara, Ms. Lescaudron), Medeos (Ms. Charles, Ms. Bichout), Domusvi (Mr. Virgile, Mr. Hardy, Mr. Solheim), Orpéa (Ms. Feist, Ms. Mousis, Ms. Laurent), Mgen (Ms. Santangéli), Colisee (Ms. Alemany) and Les Opalines (Ms. Putzu). Our special thanks for the contributions made by all the management and coordinating doctors in the various nursing homes (Dr Teissier, Dr Clot-Faybesse, Dr San José, Dr Manes, Dr Gauthier, Dr Michel, Dr Labarriere, Dr Drancourt, Dr Morel-Roux, Dr Mayan, Dr Alves de Quiera, Dr Blanc Fattin, Dr Benedetti, Dr Di Léo Massiani, Dr Gil), and for the support of the EMAI Clinical Research Network (Sanchez D, Dimier C, Hugues E, Verdier V, Agnelli L). Finally, our thanks to Jude Sweeney for the English revision and editing of our manuscript.

\section{Author Contributions}

PV1, AD and FC designed and developed the mixedmethod study protocol, coordinated Phase 1 (acceptability) and will coordinate Phases 2 and 3 (satisfaction).

MC, PV1, AD and FC managed the literature searches and developed the research questions. MC conducted and transcribed the interviews, performed the analysis and wrote the first draft of the manuscript.

AK participated in drafting the regulatory files, submitted them to the administrative institutions (French regional ethical committee, French drug and device regulation agency).

All authors made substantial contributions to conception and design, acquisition of data, or analysis and interpretation of data, took part in drafting the article or revising it critically for important intellectual content, agreed to submit to the current journal, gave final approval of the version to be published, and agree to be accountable for all aspects of the work.

\section{Funding}

This trial is being supported by the French Ministry of Health through institutional grants from the French 2017 National Programme for Clinical Research (Programme de Recherche sur la Performance du Système de Soins). The Assistance Publique-Hôpitaux de Marseille is the study promoter and is in charge of all administrative measures. The trial is registered at ClinicalTrials.gov under the number NCT03640845.

\section{Disclosure}

Florian Correard reports grants from PREPS-2017-0574, during the conduct of the study; personal fees from NOVARTIS, personal fees from PIERRE FABRE, personal fees from ASTRAZENECA, personal fees from BMS, outside the submitted work. Maeva Montaleytang reports grants from PREPS-2017-0574, during the conduct of the study. Stephane Honore report grants from DGOS (French government), during the conduct of the study. The authors report no other potential conflicts of interest for this work.

\section{References}

1. Herr M, Grondin H, Sanchez S, et al. Polypharmacy and potentially inappropriate medications: a cross-sectional analysis among 451 nursing homes in France. Eur J Clin Pharmacol. 2017;73(5):601-608. doi:10.1007/s00228-016-2193-z

2. Lazarou J, Pomeranz BH, Corey PN. Incidence of adverse drug reactions in hospitalized patients: a meta-analysis of prospective studies. JAMA. 1998;279(15):1200-1205. doi:10.1001/ jama.279.15.1200

3. O'Mahony D, Cherubini A, Petrovic M. Optimizing pharmacotherapy in older patients: a European perspective. Drugs Aging. 2012;29 (6):423-425. doi:10.2165/11630990-000000000-00000

4. Gurwitz JH, Field TS, Harrold LR, et al. Incidence and preventability of adverse drug events among older persons in the ambulatory setting. JAMA. 2003;289(9):1107-1116. doi:10.1001/jama.289.9.1107

5. Mallet L, Spinewine A, Huang A. The challenge of managing drug interactions in elderly people. Lancet Lond Engl. 2007;370 (9582):185-191. doi:10.1016/S0140-6736(07)61092-7

6. Fialová D, Onder G. Medication errors in elderly people: contributing factors and future perspectives. Br J Clin Pharmacol. 2009;67 (6):641-645. doi:10.1111/j.1365-2125.2009.03419.x

7. Hughes CM. Medication non-adherence in the elderly: how big is the problem? Drugs Aging. 2004;21(12):793-811. doi:10.2165/ 00002512-200421120-00004

8. Sganga F, Landi F, Ruggiero C, et al. Polypharmacy and health outcomes among older adults discharged from hospital: results from the CRIME study. Geriatr Gerontol Int. 2015;15(2):141-146. doi:10.1111/ggi.12241

9. Scott IA, Hilmer SN, Reeve E, et al. Reducing inappropriate polypharmacy: the process of deprescribing. JAMA Intern Med. 2015;175 (5):827-834. doi:10.1001/jamainternmed.2015.0324

10. AlRasheed MM, Alhawassi TM, Alanazi A, Aloudah N, Khurshid F, Alsultan M. Knowledge and willingness of physicians about deprescribing among older patients: a qualitative study. Clin Interv Aging. 2018;13:1401-1408. doi:10.2147/CIA.S165588 
11. Wallis KA, Andrews A, Henderson M. Swimming against the tide: primary care physicians' views on deprescribing in everyday practice. Ann Fam Med. 2017;15(4):341-346. doi:10.1370/afm.2094

12. Ailabouni NJ, Nishtala PS, Mangin D, Tordoff JM. Challenges and enablers of deprescribing: a general practitioner perspective. PLoS One. 2016;11(4):e0151066. doi:10.1371/journal.pone.0151066

13. Djatche L, Lee S, Singer D, Hegarty SE, Lombardi M, Maio V. How confident are physicians in deprescribing for the elderly and what barriers prevent deprescribing? J Clin Pharm Ther. 2018;43(4):550 555. doi:10.1111/jcpt. 12688

14. Correard F, Montaleytang M, Costa M, et al. Impact of medication review via tele-expertise on unplanned hospitalizations at 3 months of nursing homes patients (TEM-EHPAD): study protocol for a randomized controlled trial. BMC Geriatr. 2020;20(1):147. doi:10.1186/s12877-020-01546-3

15. Bashshur RL, Howell JD, Krupinski EA, Harms KM, Bashshur N, Doarn CR. The empirical foundations of telemedicine interventions in primary care. Telemed $J$ E Health. 2016;22(5):342-375. doi:10.1089/tmj.2016.0045

16. Davis MM, Freeman M, Kaye J, Vuckovic N, Buckley DI. A systematic review of clinician and staff views on the acceptability of incorporating remote monitoring technology into primary care. Telemed J E-Health off J Am Telemed Assoc. 2014;20(5):428-438. doi:10.1089/tmj.2013.0166

17. Ekeland AG, Bowes A, Flottorp S. Effectiveness of telemedicine: a systematic review of reviews. Int J Med Inf. 2010;79(11):736-771. doi:10.1016/j.ijmedinf.2010.08.006

18. Zulfiqar AA, Hajjam A, Talha S, et al. Telemedicine and geriatrics in France: inventory of experiments. Curr Gerontol Geriatr Res. 2018;2018:9042180. doi:10.1155/2018/9042180

19. Hanlon P, Daines L, Campbell C, McKinstry B, Weller D, Pinnock H. Telehealth interventions to support self-management of long-term conditions: a systematic metareview of diabetes, heart failure, asthma, chronic obstructive pulmonary disease, and cancer. $\mathrm{J} \mathrm{Med}$ Internet Res. 2017;19(5):e172. doi:10.2196/jmir.6688

20. Bashi N, Karunanithi M, Fatehi F, Ding H, Walters D. Remote monitoring of patients with heart failure: an overview of systematic reviews. J Med Internet Res. 2017;19(1):e18. doi:10.2196/ jmir. 6571

21. De Luca R, Bramanti A, De Cola MC, et al. Tele-health-care in the elderly living in nursing home: the first Sicilian multimodal approach. Aging Clin Exp Res. 2016;28(4):753-759. doi:10.1007/s40520-0150463-8

22. Graham ID, Logan J, Davies B, Nimrod C. Changing the use of electronic fetal monitoring and labor support: a case study of barriers and facilitators. Birth Berkeley Calif. 2004;31(4):293-301. doi:10.1111/j.0730-7659.2004.00322.x

23. Creswell J, Plano Clark V. Designing and Conducting Mixed Methods Research. 2nd ed. Thousand Oaks: Sage Publications; 2011.

24. Braun V, Clarke V. What can "thematic analysis" offer health and wellbeing researchers? Int J Qual Stud Health Well-Being. 2014;9 (26152).

25. Bradley EH, Curry LA, Devers KJ. Qualitative data analysis for health services research: developing taxonomy, themes, and theory. Health Serv Res. 2007;42(4):1758-1772. doi:10.1111/j.14756773.2006.00684.x

26. Cohen DJ, Crabtree BF. Evaluative criteria for qualitative research in health care: controversies and recommendations. Ann Fam Med. 2008;6(4):331-339. doi:10.1370/afm.818

27. Clark PG. Values in health care professional socialization: implications for geriatric education in interdisciplinary teamwork. Gerontologist. 1997;37(4):441-451. doi:10.1093/geront/37.4.441

28. Ajjawi R, Higgs J. Learning to reason: a journey of professional socialisation. Adv Health Sci Educ Theory Pract. 2008;13(2):133150. doi:10.1007/s10459-006-9032-4
29. Aguilar A, Stupans I, Scutter S, King S. Exploring professionalism: the professional values of Australian occupational therapists. Aust Occup Ther J. 2012;59(3):209-217. doi:10.1111/j.14401630.2012.00996.x

30. Maidment ID, Damery S, Campbell N, et al. Medication review plus person-centred care: a feasibility study of a pharmacy-health psychology dual intervention to improve care for people living with dementia. BMC Psychiatry. 2018;18. doi:10.1186/s12888-018-1907-4

31. Cardwell K, Clyne B, Moriarty F, et al. Supporting prescribing in Irish primary care: protocol for a non-randomised pilot study of a general practice pharmacist (GPP) intervention to optimise prescribing in primary care. Pilot Feasibility Stud. 2018;4:122. doi:10.1186/ s40814-018-0311-7

32. Wilchesky M, Mueller G, Morin M, et al. The OptimaMed intervention to reduce inappropriate medications in nursing home residents with severe dementia: results from a quasi-experimental feasibility pilot study. BMC Geriatr. 2018;18(1):204. doi:10.1186/s12877-0180895-z

33. Desveaux L, Saragosa M, Rogers J, et al. Improving the appropriateness of antipsychotic prescribing in nursing homes: a mixed-methods process evaluation of an academic detailing intervention. Implement Sci IS. 2017;12. doi:10.1186/s13012-017-0602-z

34. Krska J, Gill D, Hansford D. Pharmacist-supported medication review training for general practitioners: feasibility and acceptability. Med Educ. 2006;40(12):1217-1225. doi:10.1111/j.13652929.2006.02633.x

35. Schuling J, Gebben H, Veehof LJG, Haaijer-Ruskamp FM. Deprescribing medication in very elderly patients with multimorbidity: the view of Dutch GPs: a qualitative study. BMC Fam Pract. 2012;13:56. doi:10.1186/1471-2296-13-56

36. Moen J, Norrgård S, Antonov K, Nilsson JLG, Ring L. GPs' perceptions of multiple-medicine use in older patients. J Eval Clin Pract. 2010;16(1):69-75. doi:10.1111/j.1365-2753.2008.01116.x

37. Schöpf AC, von Hirschhausen M, Farin E, Maun A. Elderly patients' and GPs' perspectives of patient-GP communication concerning polypharmacy: a qualitative interview study. Prim Health Care Res Dev. 2018;19(4):355-364. doi:10.1017/S1463423617000883

38. Gaugler JE. Family involvement in residential long-term care: a synthesis and critical review. Aging Ment Health. 2005;9(2):105118. doi:10.1080/13607860412331310245

39. Gladstone JW, Dupuis SL, Wexler E. Ways that families engage with staff in long-term care facilities. Can J Aging Rev Can Vieil. 2007;26 (4):391-402. doi:10.3138/cja.26.4.391

40. Laffon de Mazières C, Lapeyre-Mestre M, Vellas B, de Souto Barreto $\mathrm{P}$, Rolland Y. Organizational factors associated with inappropriate neuroleptic drug prescribing in nursing homes: a multilevel approach. $J$ Am Med Dir Assoc. 2015;16(7):590-597. doi:10.1016/j. jamda.2015.01.092

41. Schmidt-Mende K, Hasselström J, Wettermark B, Andersen M, Bastholm-Rahmner P. General practitioners' and nurses' views on medication reviews and potentially inappropriate medicines in elderly patients - a qualitative study of reports by educating pharmacists. Scand J Prim Health Care. 2018;36(3):329-341. doi:10.1080/ 02813432.2018 .1487458

42. Joseph V, West RM, Shickle D, Keen J, Clamp S. Key challenges in the development and implementation of telehealth projects. J Telemed Telecare. 2011;17(2):71-77. doi:10.1258/jtt.2010.100315

43. Kayyali R, Hesso I, Mahdi A, Hamzat O, Adu A, Nabhani Gebara S. Telehealth: misconceptions and experiences of healthcare professionals in England. Int $J$ Pharm Pract. 2017;25(3):203-209. doi:10.1111/ijpp. 12340

44. Brewster L, Mountain G, Wessels B, Kelly C, Hawley M. Factors affecting front line staff acceptance of telehealth technologies: a mixed-method systematic review. J Adv Nurs. 2014;70(1):21-33. doi:10.1111/jan.12196 
45. Merkel S, Kucharski A. Participatory design in gerontechnology: a systematic literature review. Gerontologist. 2019;59(1):e16-e25. doi:10.1093/geront/gny034

46. Marien S, Legrand D, Ramdoyal R, et al. A User-Centered design and usability testing of a web-based medication reconciliation application integrated in an eHealth network. Int $J$ Med Inf. 2019;126:138-146. doi:10.1016/j.ijmedinf.2019.03.013

47. van der Biezen M, Wensing M, Poghosyan L, van der Burgt R, Laurant M. Collaboration in teams with nurse practitioners and general practitioners during out-of-hours and implications for patient care; a qualitative study. BMC Health Serv Res. 2017;17(1):589. doi:10.1186/s12913-017-2548-x

48. Leonard M, Graham S, Bonacum D. The human factor: the critical importance of effective teamwork and communication in providing safe care. Qual Saf Health Care. 2004;13(Suppl 1):i85-90. doi:10.1136/qhc.13.suppl_1.i85
49. Mazzocco K, Petitti DB, Fong KT, et al. Surgical team behaviors and patient outcomes. Am J Surg. 2009;197(5):678-685. doi:10.1016/j. amjsurg.2008.03.002

50. Hagaman AK, Wutich A. How many interviews are enough to identify metathemes in multisited and cross-cultural research? Another perspective on Guest, Bunce, and Johnson's (2006) Landmark study. Field Methods. 2017;29(1):23-41. doi:10.1177/ $1525822 X 16640447$

\section{Publish your work in this journal}

Clinical Interventions in Aging is an international, peer-reviewed journal focusing on evidence-based reports on the value or lack thereof of treatments intended to prevent or delay the onset of maladaptive correlates of aging in human beings. This journal is indexed on PubMed Central, MedLine, CAS, Scopus and the Elsevier
Bibliographic databases. The manuscript management system is completely online and includes a very quick and fair peer-review system, which is all easy to use. Visit http://www.dovepress.com/ testimonials.php to read real quotes from published authors. 